\title{
Efficacy of Home-Based Fortified Diet in Rehabilitation of Malnourished Children in Resource Restrained Country: An Institution Based Retrospective Study
}

\author{
Saba Shahid ( $\nabla$ saba.shahid@tih.org.pk) \\ INDUS Hospital \\ Marvi Mahesar \\ INDUS Hospital \\ Anum Rahim \\ INDUS Hospital \\ Yumna Sadiq \\ INDUS Hospital
}

Research article

Keywords: Malnutrition, children, home fortified diet, weight gain, anemia, and rickets

Posted Date: August 28th, 2020

DOl: https://doi.org/10.21203/rs.3.rs-60166/v1

License: (c) (1) This work is licensed under a Creative Commons Attribution 4.0 International License.

Read Full License

Version of Record: A version of this preprint was published at BMC Nutrition on August 13th, 2021. See the published version at https://doi.org/10.1186/s40795-021-00455-x. 


\section{Abstract}

Background: Globally, it is estimated that 50 million children under five are wasted. National nutrition survey-2018 has shown that $23.3 \%$ and $45.5 \%$ of children are wasted and stunted in Pakistan. Many studies have shown that hospital-based management of malnutrition is not practical due to high cost and iatrogenic infections and currently WHO recommends community-based management of malnutrition with provision of therapeutic food. There is limited evidence of community rehabilitation of malnourished children by using home fortified diet in Pakistan. This study aims to evaluate effectiveness of using energy dense, home fortified diet in weight gain of malnourished children in Karachi, through a retrospective chart review.

Methods: A retrospective chart review of pediatric patients (aged 6 month- 5 years) seen in Indus Hospital between January 2017 to June 2018 was conducted. A pre-designed data abstraction form was used to record detailed information about demographic characteristics, feeding, anthropometric, micronutrient, and nutritional details at enrollment and on follow-up.

Results: A total of 361 patients were included in the final analysis. The median age (IQR) of children was 15 (14) months. Forty eight percent $(n=172)$ children had diarrhea and $54 \%(n=195)$ children had respiratory tract infection. The median length of stay in the program was 28 days. The median (IQR) for average weight gain was $4.8(0-10.3) \mathrm{g} / \mathrm{Kg} /$ day, 64.6\% $(\mathrm{n}=226)$ children defaulted, $29 \%(\mathrm{n}=102)$ were cured and $3 \%(n=10)$ died.

Conclusion: This study revealed adequate weight gain and recovery in malnourished children by using home fortified diet in real life situations without using therapeutic food or monetary support. Home fortified diets may serve as effective strategy in community-based rehabilitation of malnourished children.

\section{Background}

Globally, it is estimated that in year 2019, 144 million children under five were wasted and 47 million were wasted and South Asia is the epicenter of the global burden of wasting and stunting (1). National nutrition survey-2018 of Pakistan also reflects high burden of malnutrition in children under 5 years. Around $23.3 \%$ and $45.5 \%$ of children are wasted and stunted in Pakistan and highest rate of malnutrition is reported from Sindh province (2).

Before 2007, WHO advocated inpatient treatment of malnourished children (3). However facility-based management did not prove to be practical due to several constraints which included high cost of management, iatrogenic infections and cost to families due to prolonged hospital stay (4). Therefore in 2007, WHO recommended that management of uncomplicated severe acute malnutrition (SAM) should be in community-based settings (2).In order to ensure optimal diet for community management, in resource-restrained countries UNICEF recommended either use of therapeutic diets like Ready to use 
therapeutic feed (RUTF) (5) and Corn Soya Blend (CSB) (6) or fortification of local diet with products like Micro Nutrient Powder (MNP) (7).

Products like therapeutic feed are costly. They depend on import of ingredients and presence of infrastructure for their manufacture. In Pakistan government-run programs supply local or international produced RUTF to selected rural and urban areas (8-11). The supply of RUTF is erratic and selective as a result, many urban and rural areas remain deprived of nutritional supplements. The caregivers in areas where there is no RUTF supplementation rely on unfortified indigenous food products for feeding children, which results in lack of dietary diversity and acceptable diet remains less than recommended values (2).

One logical, cost effective and feasible method of improving the quality and nutritive value of complementary food in Pakistani households is to enrich the existing recipes with locally available nutridense products (8). Efficacy of fortified; home-based foods in Pakistan should be assessed in real life situations, especially in poor urban communities of Pakistan where there is no constant supply of therapeutic food or external monetary support. We did not find any local study on effectiveness of fortified local recipes. Hence, this study aimed to evaluate effectiveness of using energy dense, home fortified diet in weight gain of malnourished children in Karachi, through a retrospective chart review.

\section{Methods}

\section{Study area and period}

Institution based retrospective cohort study was conducted from January 2017 to June 2018. The study was conducted at The Indus Hospital, which is a tertiary care facility in the suburbs of Karachi, Pakistan. Around 1200-1300 malnourished children are seen annually in this hospital, which include a mix of severe acute malnutrition (SAM) and moderate acute malnutrition (MAM). Community based rehabilitation of uncomplicated malnourished children is done in outpatient department of Indus Hospital by counseling and recommendation of fortified home-based staple diet plans with regular follow up.

\section{Sample size and sampling procedure}

All children with ages ranging from 6-59 months with malnutrition, that had been treated at Indus nutrition rehabilitation clinic (NRC), from January 2017 to June 2018were included in the study. Those children who did not have proper records were excluded from the study. Children with secondary malnutrition due to other medical conditions or children who had edema due to other causes were also excluded from the study.

\section{Treatment protocol}

Nutrition rehabilitation clinic (NRC) is conducted twice weekly in the outpatient department of Indus Hospital. The clinic caters to malnourished children with ages ranging from 6 month- 5 years. Malnutrition is diagnosed based on weight, height and mid upper arm circumference cut-off values prescribed by WHO. At enrollment nutritional details of each child is recorded on pilot tested, predesigned 
questionnaire which includes nutritional history and details of physical examination. Examination is done for anthropometry and clinical features like edema, dermatosis, anemia, rickets and eye changes. If there are clinical signs of malnutrition, then relevant labs are sent. Children with rickets and anemia are treated with oral iron and vitamin D3 supplements. The dosages of iron and vitamin D are prescribed according to WHO protocols. If there is severe anemia children are transfused. Vitamin B12 deficiency is treated with oral Cobalamin according to institutional protocol. All the malnourished children are given multiple micronutrient powder (MNP) and zinc supplements. Antibiotics are given when needed.

Mothers are counseled on age appropriate feeding practices and hygiene strategies through Infant young child feeding practices (IYCF) counseling cards. Caregivers are counseled on preparing recipes of various nutrient dense home-based diets. The diet plans are made by the nutritionist at Indus hospital using ingredients which are indigenous and available in normal households. Demonstration for quantity and texture of food is done by showing spoons and measuring cups. Brochures containing pictorial and written instructions in Urdu are also given to the mothers. Meal frequencies ranging from 2-6 times per day are advised based on age of child. For non-breast-fed children milk and milk products are added. About $150-220 \mathrm{Kcal} / \mathrm{kg} /$ day of calories and $3-5 \mathrm{~g} / \mathrm{kg} /$ day of proteins are advised. Calories and proteins are gradually escalated in the diet.

Children are regularly followed according to severity of malnutrition. Moderately malnourished children are followed 3 weekly whereas severely malnourished children are followed fortnightly. At every follow up visit history taking and physical examination is done along with nutritional counseling. If a child is absent for 6 consecutive weeks, then he is considered as defaulter. The child is considered recovered when weight for height/length Z- score is $\geq-1.0 \mathrm{SD}$, or mid upper arm circumference is $>12.5 \mathrm{~cm}$, whichever comes first. The children after recovery are followed for 2 months to ensure continuous weight gain.

\section{Operational definition}

Severe acute malnutrition (SAM): SAM is labeled if any of the three criteria is present (i) weight for height/length Z- score $<-3.0$, or (ii) mid upper arm circumference $<11.5 \mathrm{~cm}$, or (iii) pitting pedal edema (3).

Moderate acute malnutrition (MAM): MAM is labeled if weight for height/length Z- score is $<-2.0$, or (ii) mid upper arm circumference is between $11.5-12.5 \mathrm{~cm}(3)$.

Anemia: Severe when hemoglobin is less than $6 \mathrm{~g} / \mathrm{dl}$ and moderate when hemoglobin level is between $6.1-11 \mathrm{~g} / \mathrm{dl}(3)$.

Vitamin B12 deficiency: Plasma vitamin B 12 level < 203 pg/mL (12).

Rickets: Serum 25(OH) D levels at $<30 \mathrm{nmol} / \mathrm{L}$ with or without clinical signs of Rickets (13).

Weight gain: Weight gain is calculated in $\mathrm{g} / \mathrm{Kg} / \mathrm{day} .5 \mathrm{~g} / \mathrm{kg} /$ day is considered adequate weight gain (14).

Edema: Presence of pitting edema on dorsum of feet or shin of legs or peri-orbital edema 


\section{Data collection procedure}

A structured data abstraction form was used for data collection. Data was gathered for demographic characteristics, feeding, micronutrient, anthropometric and nutritional details at enrollment and on followup. Data was collected by nutritionists and doctor. The data abstraction form was adopted from WHO guidelines (3) and Sphere standard for management of severe acute malnutrition (14).

\section{Data management and analysis}

The statistical analysis was performed using Stata 16.0 software. Normality assessment of continuous variables was done on the basis of skewness and kurtosis. Normally distributed variables were reported as mean [SD] whereas median (IQR) was calculated for skewed variables. Paired T test was applied to compare the entry and exit variables for normally distributed variables, while Wilcoxon sign rank test was used for non-normal data. The categorical data was presented as frequencies and percentages.

McNemars test was applied to measure the difference between $(2 \times 2)$ variables, whereas others with more than two categories were assed via McNemars Bowker test. $P$ value $<0.05$ was considered to be significant.

\section{Results}

\section{Participants}

A total of 490 children were screened for malnutrition, out of these 129 children were excluded, 69 children were excluded as they had only micronutrient deficiencies with normal anthropometry. 60 children were excluded due to chronic illnesses (Fig. 1).

Figure 1: Flow chart of patients' enrolment and outcome

A total of 361 patients were included in the final analysis. The median age of children was 15 (IQR 14) months, more than half of the patients were female $(53.5 \%, n=193)$. Maximum numbers of children were from Korangi 48.5\% $(n=175)$ district. Diarrhea and respiratory tract infections were most common infections, 48\% $(n=172)$ children had diarrhea and $54 \%(n=195)$ children had respiratory tract infection at time of enrollment. Of the 361 patients, $98.3 \%(n=355)$ were malnourished at the time of enrolment on the basis of either MUAC or SD score or both (Table 1). 
Table 1

Baseline characteristics of children

\begin{tabular}{|ll|}
\hline Variable (N) & Frequency $\mathbf{n}$ (\%) \\
\hline Age in months* (359) & $14(15)$ \\
\hline District (358) & \\
\hline West & $7(2.0)$ \\
\hline East & $18(5.0)$ \\
\hline Central & $8(2.2)$ \\
\hline South & $9(2.5)$ \\
\hline Malir & $107(29.9)$ \\
\hline Korangi & $175(48.9)$ \\
\hline Other & $34(9.5)$ \\
\hline Gender (361) & \\
\hline Male & $168(46.5)$ \\
\hline Female & $193(53.5)$ \\
\hline Type of Feed (134) & \\
\hline Exclusive breast feeding & $48(35.8)$ \\
\hline Top feed & 66(49.3) \\
\hline Combination feeding & $20(14.9)$ \\
\hline Vitamin D Deficiency (218) \\
\hline Present & $116(53.2)$ \\
\hline Absent & $102(46.8)$ \\
\hline Anemia (253) & \\
\hline Present & $213(84.2)$ \\
\hline Absent & $40(15.8)$ \\
\hline Vitamin A Deficiency (245) \\
\hline Present & \\
\hline Absent & \\
\hline Dermatosis (347) & \\
\hline Present & \\
\hline
\end{tabular}




\begin{tabular}{|lc|}
\hline Variable (N) & Frequency $\mathbf{n}$ (\%) \\
\hline Absent & $338(97.4)$ \\
\hline Odema (349) & \\
\hline Present & $21(6.0)$ \\
\hline Absent & $328(94.0)$ \\
\hline Otitis media (344) & \\
\hline Present & $5(1.5)$ \\
\hline Absent & $339(98.6)$ \\
\hline Respiratory Tract Infection (RTI) (352) \\
\hline Present & $182(51.7)$ \\
\hline Absent & $170(48.3)$ \\
\hline Diarrhea (305) & \\
\hline Present & $161(52.8)$ \\
\hline Absent & $144(47.2)$ \\
\hline MUAC at enrollment (357) & \\
\hline Normal & $4(1.1)$ \\
\hline MAM & $104(29.1)$ \\
\hline SAM & $249(69.8)$ \\
\hline SD score Enrollment (160) & \\
\hline Normal & $15(9.4)$ \\
\hline MAM & $51(31.9)$ \\
\hline SAM & $94(58.8)$ \\
\hline *Median (IQR) & \\
\hline
\end{tabular}

\section{Analysis Of Primary Outcomes}

Outcomes of $96 \%(n=350)$ patients are known; of these, $64.6 \%(n=226)$ were defaulters, $29 \%(n=102)$ were cured and $3 \%(n=10)$ died (Table 2). There was significant difference ( $p$ value $=0.00)$ in the number of patients who were cured on the basis of MUAC and SD score. Over all 102 patients were cured. Of these, $75.5 \%(n=77)$ were considered to be cured on the basis of MUAC, while $20 \%(n=20)$ were considered to be cured on the basis of SD score and $5 \%(n=5)$ were cured on the basis of both 
(Table 2).The median (IQR) for average stay in the program was 28 days. The median (IQR) for average weight gain was $4.8(\mathrm{~g} / \mathrm{Kg} /$ day) (Table 2$)$.

Table 2

Outcomes at completion of study

\begin{tabular}{|ll|}
\hline Variable (N) & Frequency $\mathbf{n}(\%)$ \\
\hline Duration of stay in the program* (302) & $28(101)$ \\
\hline Weight gain g/Kg/day* (181) & $4.8(10.3)$ \\
\hline No of follow-ups & $263(72.9)$ \\
\hline 0 & $56(15.5)$ \\
\hline 1 & $20(5.5)$ \\
\hline 2 & $22(6.1)$ \\
\hline 3 & $59(60.2)$ \\
\hline Infection developed during treatment (98) \\
\hline Yes & $39(39.8)$ \\
\hline Cure on basis of anthropometry (102) & \\
\hline MUAC & $77(75.5)$ \\
\hline SD score & $20(19.6)$ \\
\hline Both & $5(4.9)$ \\
\hline Outcome status (350) & $12(3.4)$ \\
\hline defaulter & $226(64.6)$ \\
\hline cured & $102(29.1)$ \\
\hline expired & $10(2.9)$ \\
\hline ongoing & \\
\hline$*$ Median (IQR) & \\
\hline
\end{tabular}

\section{Analysis Of Secondary Outcomes}

There was significant difference in anemia and rickets status of the patients at the time on enrolment compared to the time of exit; 24 children (6.8\%) had severe anemia at time of enrollment which had reduced to 3 children (3\%) at time of exit ( $p$-value: 0.0 ). Rickets was observed in 101 children (53\%) at 
enrollment while at exit 5 children (17\%) had rickets (p-value: 0.04). Recovery from vitamin B12 and Folate deficiency was not statistically significant, 49 children (32\%) had vitamin B12 deficiency, out of which 45 children got cured ( $p$-value: 1$)$. Five children had Folate deficiency, and all got cured ( $p$-value: 1), (Table 3). 
Table 3

Comparison of Status of anthropometry and micronutrients among children at enrollment and exit

\begin{tabular}{|c|c|c|c|}
\hline Variable & At Entry n (\%) & At Exit n (\%) & $P$ Value \\
\hline \multicolumn{3}{|l|}{ Nutritional status on MUAC } & \multirow{4}{*}{$0.00^{¥}$} \\
\hline Normal & $4(1.1)$ & $82(30.7)$ & \\
\hline SAM & $104(29.1)$ & $71(26.6)$ & \\
\hline MAM & $249(69.8)$ & $114(42.7)$ & \\
\hline \multicolumn{3}{|l|}{ Nutritional status on SD score } & \multirow{4}{*}{$0.00^{¥}$} \\
\hline Normal & $15(9.4)$ & $25(37.3)$ & \\
\hline SAM & $51(31.9)$ & $26(38.8)$ & \\
\hline MAM & $94(58.8)$ & 16(23.9) & \\
\hline \multicolumn{3}{|l|}{ Anemia (on basis of $\mathrm{Hb}$ ) } & \multirow[t]{5}{*}{$0.00^{¥}$} \\
\hline Normal & $56(15.9)$ & $23(21.5)$ & \\
\hline Mild Anemia & $74(21)$ & $26(24.3)$ & \\
\hline Moderate & 198(56.3) & $55(51.4)$ & \\
\hline Severe Anemia & $24(6.8)$ & $3(2.8)$ & \\
\hline \multicolumn{3}{|l|}{ Vitamin D (on basis of $25(\mathrm{OH})$ D level) } & \multirow[t]{3}{*}{$0.04^{4}$} \\
\hline Normal & $88(46.6)$ & $24(82.8)$ & \\
\hline Deficient & $101(53.4)$ & $5(17.2)$ & \\
\hline \multicolumn{3}{|l|}{ Folate } & \multirow[t]{3}{*}{$1.00^{9}$} \\
\hline Normal & $54(91.5)$ & $11(100)$ & \\
\hline Deficient & $5(8.5)$ & $0(0)$ & \\
\hline \multicolumn{3}{|l|}{ B 12 (on basis of serum levels) } & \multirow[t]{3}{*}{$1.00^{9}$} \\
\hline Normal & 104(68) & $34(89.5)$ & \\
\hline Deficient & $49(32)$ & $4(10.5)$ & \\
\hline Height* & $69(63-74.3)$ & $72(60-77)$ & $0.00 €$ \\
\hline Weight & $6.2(1.7)$ & $7.1(1.8)$ & $0.00^{\bigotimes}$ \\
\hline
\end{tabular}

Two hundred and twenty six children (65\%) patients did not follow up in the OPDs regularly out of which $73 \%(n=26)$ never came after initial visit while 22 children $(6 \%)$ came for 3 visits, (Table 2$)$. There was no 
significant difference between males and females in the number of follow ups. Children who came for maximum number of follow ups belonged to Korangi district; $49 \%(n=175)$ While children belonging to district West $2 \%(n=7)$ had least number of follow-ups (Fig. 2).

\section{Discussion}

This study analyzed efficacy of using fortified, energy dense, home prepared diet, in rehabilitation of uncomplicated malnourished children, aged 6 to 59 months, treated in a tertiary care hospital. Findings of this study showed that median age of children was 14 months. Out of 361 enrolled children, $65 \%(n=$ 226) were defaulters, $30 \%(n=102)$ were cured and $2.9 \%(n=10)$ died. The average stay in nutrition rehabilitation program was 28 days. The average weight gain of the children was $4.8 \mathrm{~g} / \mathrm{kg} / \mathrm{day}$.

In our study we were able to achieve weight gain more than $4 \mathrm{~g} / \mathrm{kg} /$ day, which is WHO minimum standard for community treatment of malnourished children (15). We did not achieve good weight gain (5$10 \mathrm{~g} / \mathrm{Kg} /$ day), which is stated to be in range of $5-10 \mathrm{~g} / \mathrm{kg} /$ day according to SPHERE standards (14). The low weight gain in our study could be because of multiple factors, which may include lack of mothers' compliance in preparation of recipes, in- frequent feeding of children, food sharing at home and unhygienic feeding practices. An additional explanation of slow weight gain in our study could be high rate of infections both at enrollment and follow up. We observed that $54 \%$ and $48 \%$ children had respiratory tract infections and diarrhea respectively. The infections could be due poor hygienic conditions and incomplete vaccination status of the children in our study.

Several studies have shown weight gain ranging from $1.7 \mathrm{~g} / \mathrm{kg} /$ day to $8.7 \mathrm{~g} / \mathrm{kg} /$ day with use of therapeutic, fortified diet (16-20).However most of these studies (2-5) were done in controlled environment, where therapeutic nutrition supplements were given to the children free of cost and regular monitoring through home visits were done. We conducted this study in real life situation without any external monetary or food support and there were no home visits, this may have contributed to slow weight gain. We measured height and weight in every follow up and used height recorded in the last follow up for calculating final WHZ score. This was done to ensure accuracy but this method shows slow recovery from malnutrition (21) and could be a contributing factor for slow weight gain in our children.

We observed high default rate, 226 (66\%) children did not come for regular follow ups despite frequent telephonic reminders. Aguayo and colleagues (22) also reported default rate of $11 \%$ while assessing community rehabilitation of malnutrition in Pakistan. In our study many children who defaulted, resided in close proximity to our hospital. We observed that many defaulted children continued to have infections till their last follow up. There is a possibility that parents considered infections as poor recovery and stopped coming to hospital due to this reason. Parents' lack of understanding about adverse consequences of malnutrition in their children can be another reason for default. Baig and Mahmood have reported that parents living in urban settlements of Pakistan lack awareness about importance of nutrition due low education $(23,24)$. 
World Health Organization (15) recognizes that there is difference in group of children recognized by midupper-arm circumference (MUAC) and weight-for-height Z-scores (WHZ) WHO estimated that there is $40 \%$ overlap between the two indicators in identifying malnutrition (25). We also observed difference between MUAC and WHZ scores. Seventy-seven children were cured on basis of MUAC and 20 children were cured on basis of WHZ. Grellety and Golden (26) collected data on these 2 variables from 47 countries and found out that both criteria identify different sets of malnourished children but these 2 criteria are complimentary to each other in identifying risks of mortality. He recommended that both MUAC and WHZ should be used in nutrition programs to prevent risk of mortality and under detection of cases.

\section{Strengths And Limitations Of The Study}

To the best of our knowledge, this is first study done in Pakistan which has assessed efficacy of homebased fortified diet in rehabilitation of malnourished children in real life situation without provision of food or financial support. This has important operational implications as many therapeutic nutrition centers in urban areas of Pakistan currently do not provide RUTF or offer home monitoring of children. We used both MUAC and WHZ for enrolment and exit which minimized risk of under detection of malnourished children.

We had some limitations due to a retrospective nature of study. These included missing of records in some outcome variables. We were unable to capture important socio-demographic information like parental education and household details due to insufficient data available in files.

\section{Conclusion}

This study revealed adequate weight gain and recovery in malnourished children by using home fortified diet in real life situations without using therapeutic food or monetary support. These findings may have implications for planning future nutrition programs in Pakistan, especially in urban areas. We, therefore, recommend that robust community reach out programs, using home fortified diet and effective nutritional counseling should be implemented for rehabilitation of malnourished children.

\section{Abbreviations}

National nutrition survey-2018

(5), World Health Organization:WHO, severe acute malnutrition:SAM, moderate acute malnutrition:MAM, UNICEF:United Nation Children's Fund, RUTF:Ready to use therapeutic feed, CSB:Corn Soya Blend, MNP:Micro Nutrient Powder, Infant young child feeding practices:IYCF.

\section{Declarations}

Ethics approval and consent to participate: Ethical approval was taken from the Institutional Review Board (IRB) of Interactive Research \& Development, registered with the U.S. Department of Health and 
Human Services, Office for Human Research Protections at The Indus Hospital. As the study data was a retrospective chart review, without direct interaction with patients or their caregivers, therefore, the IRB waived off the requirement of written informed consent from study participants.

Consent for publication: Not applicable

Availability of data and materials: The datasets used and/or analyzed during the current study are available from the corresponding author on reasonable request.

Competing interests: The authors declare that they have no competing interests.

Funding: No funding was received for this research.

Authors' contributions: SS and MM conceived idea of the study and participated in study design and write up. SN and ND carried out data collection, MM and ND assisted with statistical analysis. All authors were involved in the coordination of the study, drafting the manuscript and approving the final version.

Acknowledgements: Not applicable

Authors' information: ${ }^{1}$ Department of Pediatrics, The Indus Hospital, ${ }^{2}$ Department of research, Indus Hospital research center, ${ }^{3}$ Department of research, Indus Hospital research center, ${ }^{4}$ Department of Nutrition, Indus Hospital.

\section{References}

1. Organization WH. UNICEF/WHO/The World Bank Group joint child malnutrition estimates: levels and trends in child malnutrition: key findings of the 2020 edition. 2020.

2. UNICEF GoPa. National Nutrition Survey 2018 - Key Findings Report 2019 [Available from: https://www.unicef.org/pakistan/reports/national-nutrition-survey-2018-key-findings-report.

3. Organization WH. Management of severe malnutrition: a manual for physicians and other senior health workers: World Health Organization; 1999.

4. Studies NloP, Demographic MllfRD, Surveys H. Pakistan Demographic and Health Survey: National Institute of Population Studies; 2012.

5. Collins S, Dent N, Binns P, Bahwere P, Sadler K, Hallam A. Management of severe acute malnutrition in children. The lancet. 2006;368(9551):1992-2000.

6. Dewey KG. Formulations for fortified complementary foods and supplements: review of successful products for improving the nutritional status of infants and young children. Food nutrition bulletin. 2009;30(2_suppl2):239-S55.

7. De-Regil LM, Suchdev PS, Vist GE, Walleser S, Peña-Rosas JP. Home fortification of foods with multiple micronutrient powders for health and nutrition in children under two years of age. EvidenceBased Child Health: A Cochrane Review Journal. 2013;8(1):112-201. 
8. Ahmed T, Hossain M, Mahfuz M, Choudhury N, Hossain MM, Bhandari N, et al. Severe acute malnutrition in Asia. Food nutrition bulletin. 2014;35(2_suppl1):14-26.

9. Akram DS, Arif F, Khan DS, Samad S. Community based nutritional rehabilitation of severely malnourished children. JPMA The Journal of the Pakistan Medical Association. 2010;60(3):179.

10. De Bustos $C$, Basquin $C$, Rudert C. Severe acute malnutrition: an unfinished agenda in East Asia and the Pacific. Field Exchange. 2016;52:93.

11. Akram D-S, Suleman Y, Hanif HM. Home-based rehabilitation of severely malnourished children using indigenous high-density diet. J Pak Med Assoc. 2016;66(3):251-5.

12. de Benoist B. Conclusions of a WHO Technical Consultation on folate and vitamin B12 deficiencies. Food nutrition bulletin. 2008;29(2_suppl1):238-S44.

13. Greer FR. Defining vitamin D deficiency in children: beyond 25-OH vitamin D serum concentrations. Pediatrics. 2009;124(5):1471-3.

14. SPHERE HC. Minimum Standards in Humanitarian Response. The Sphere Handbook. 2018.

15. WHO W. UNSCN U. Community-based Management of Severe Acute Malnutrition: a joint statement by the World Health Organization, the world food Programme, the United Nations system standing committee on nutrition and the United Nations Children's fund. Geneva: World Health Organization, World Food Programme, United Nations System Standing Committee on Nutrition, United Nations Children's Fund; 2007.

16. Dani V, Satav K, Pendharkar J, Satav A, Ughade S, Adhav A, et al. Community-based management of severe malnutrition: SAM and SUW in the tribal area of Melghat, Maharashtra, India. Clinical Epidemiology Global Health. 2017;5(2):62-9.

17. Bhandari N, Mohan SB, Bose A, lyengar SD, Taneja S, Mazumder S, et al. Efficacy of three feeding regimens for home-based management of children with uncomplicated severe acute malnutrition: a randomised trial in India. BMJ global health. 2016;1(4).

18. Thakur GS, Singh H, Patel C. Locally-prepared ready-to-use therapeutic food for children with severe acute malnutrition: a controlled trial. Indian pediatrics. 2013;50(3):295-9.

19. Burza S, Mahajan R, Marino E, Sunyoto T, Shandilya C, Tabrez M, et al. Community-based management of severe acute malnutrition in India: new evidence from Bihar. Am J Clin Nutr. 2015;101(4):847-59.

20. Patel D, Gupta P, Shah D, Sethi K. Home-based rehabilitation of severely malnourished children in resource poor setting. Indian pediatrics. 2010;47(8):694-701.

21. Berkley J, Mwangi I, Griffiths K, Ahmed I, Mithwani S, English M, et al. Assessment of severe malnutrition among hospitalized children in rural Kenya: comparison of weight for height and mid upper arm circumference. Jama. 2005;294(5):591-7.

22. Aguayo VM, Badgaiyan N, Qadir SS, Bugti AN, Alam MM, Nishtar N, et al. Community management of acute malnutrition (CMAM) programme in $\mathrm{P}$ akistan effectively treats children with uncomplicated severe wasting. Matern Child Nutr. 2018;14:e12623. 
23. Baig-Ansari N, Rahbar MH, Bhutta ZA, Badruddin SH. Child's gender and household food insecurity are associated with stunting among young Pakistani children residing in urban squatter settlements. FoodNutr Bull. 2006;27(2):114-27.

24. Mahmood S, Nadeem S, Saif T, Mannan M, Arshad U. Nutritional status and associated factors in under-five children of Rawalpindi. Journal of Ayub Medical College Abbottabad. 2016;28(1):67-71.

25. Organization WH. WHO child growth standards and the identification of severe acute malnutrition in infants and children: joint statement by the World Health Organization and the United Nations Children's Fund. 2009.

26. Grellety E, Golden MH. Weight-for-height and mid-upper-arm circumference should be used independently to diagnose acute malnutrition: policy implications. BMC nutrition. 2016;2(1):10.

\section{Figures}

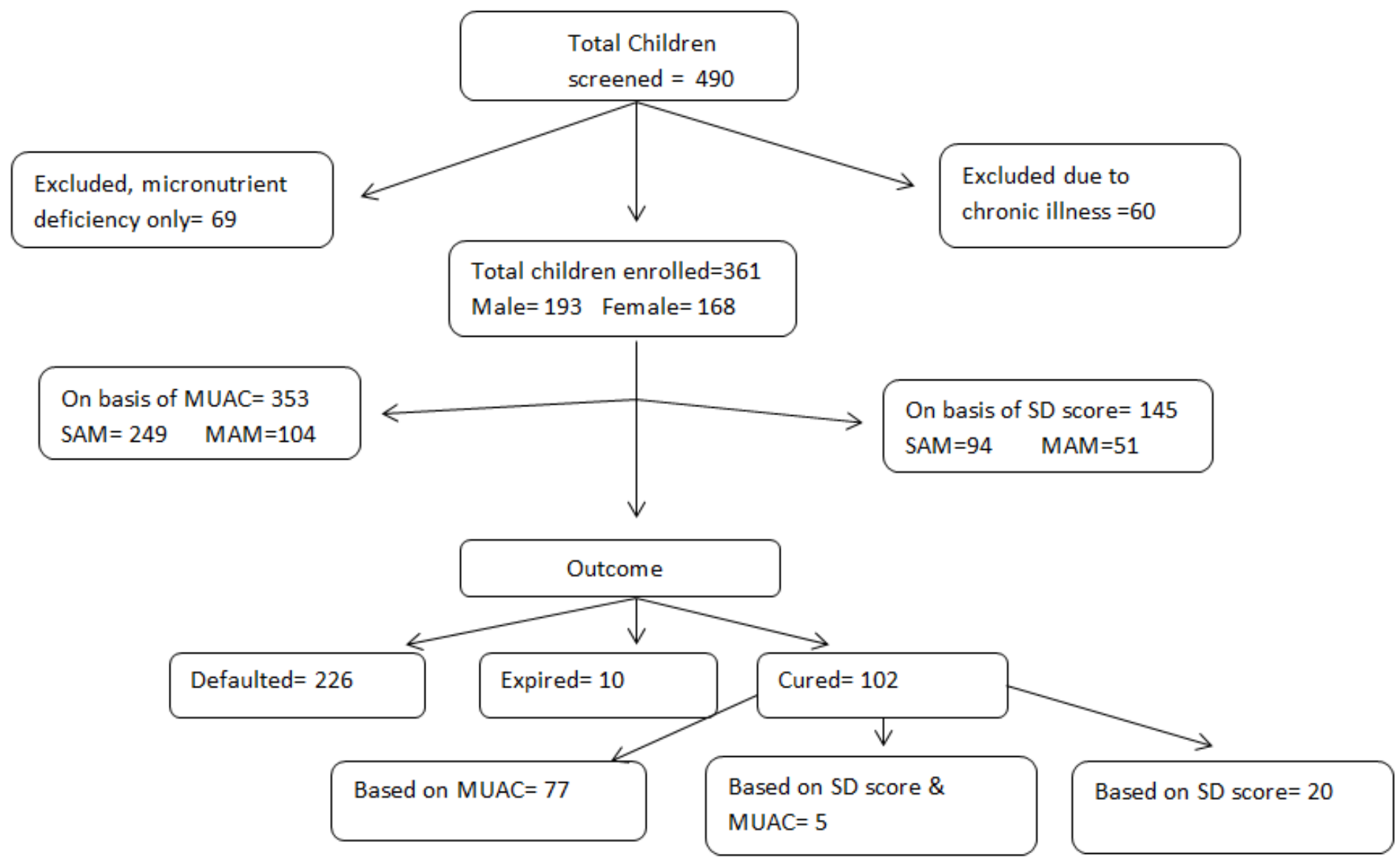

\section{Figure 1}

Flow chart of patients' enrolment and outcome 


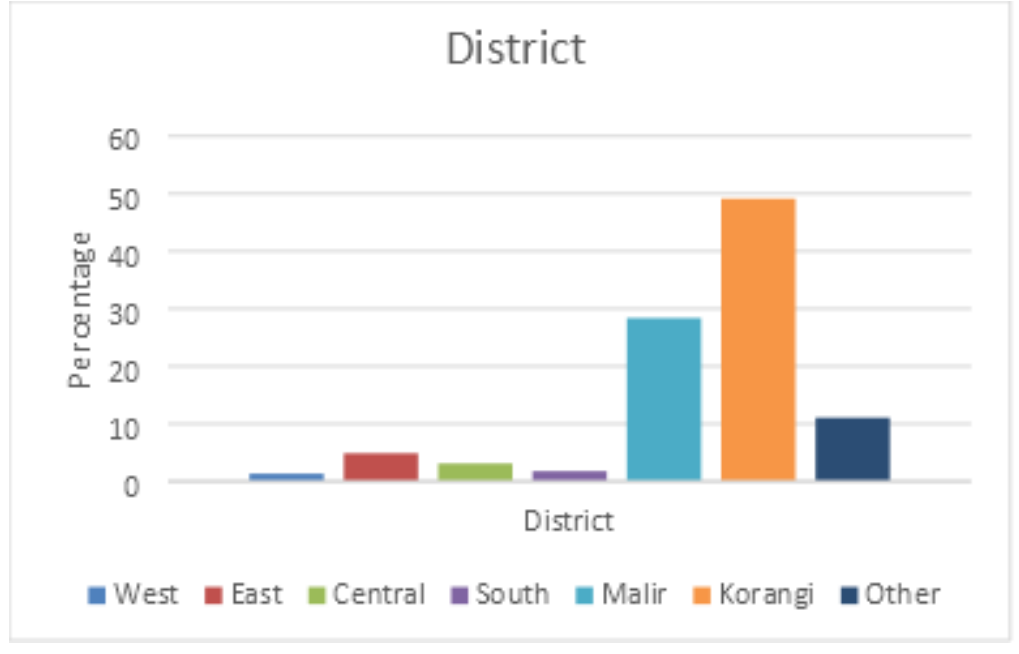

Figure 2

District distribution of the defaulted participants 